\title{
Deteksi Kecacatan Permukaan Buah Manggis Menggunakan Metode Deep Learning dengan Konvolusi Multilayer
}

(Mangosteen Rind Defect Detection using Deep Learning method with Multilayer convolution)

LAILA MARIFATUl AZIZAH, SITTI FADILLAH UMAYAH, FEBRIYANA FAJAR

\begin{abstract}
Mangosteen is one of Indonesian potential export fruits. Nevertheless, mangosteens quality is compulsary. A good quality fruit surface is needed in export fruit. This is the reason of this research to detect the flaw in rind surface, particularly mangosteen. Some researcher has been done many type of image processing for fruit detection. However, there aren't any research for mangosteen rind detection especially used Deep Learning. This research used CNN (Convolutional Neural Network) as deep learning method to detect mangosteen rind surface. Our research is to find configuration which was the best accurancy value. The rind detection calcuted between epoch and layer to obtain maximum accurancy value. This method achieved maximum value by parameter 4 layer and epoch value of 30 . From our experiment, the test result for rind detection was $98 \%$ accurancy.
\end{abstract}

Keywords: deep learning, Convolution neural network, Epoch, mangosteen.

\section{PENDAHULUAN}

Manggis (mangosteen) dengan nama latin Gracinia mangostana L. ini merupakan tanaman yang biasa tumbuh di hutan dan dataran tinggi tertentu yang beriklim tropis seperti Indonesia. Manggis merupakan penyumbang devisa terbesar Indonesia. (Sindonews, 2014) Badan Pusat Statistik Tanaman Buah dan Sayuran mencatat Ekspor manggis pada tahun 2015 mencapai US\$ 17,2 juta. Negara yang mejadi tujuan ekspor utama buah ini yaitu Thailand, Malaysia, dan Hong Kong.(Balai Besar Penelitian dan Pengembangan Pascapanen Pertanian, 2010)

Saat ini di Indonesia untuk menentukan tingkat kualitas buah manggis masih menggunakan tenaga manusia. Dengan mengandalkan alat indera pengelihatan dan peraba yang tentu setiap orang mempunyai standar penilaian yang berbeda-beda. Selain itu akan membutuhkan banyak tenaga manusia dan memakan waktu yang lama. Tidak seperti menggunakan mesin yang akan memudahkan dalam pengerjaanya. Selain itu dengan mesin yang menggunakan citra digital yang dapat memabantu pengekspor buah manggis dan mendeteksi kecacatan buah manggis secara efektif dan efisien untuk menghasilkan manggis yang layak ekspor.
Berdasarkan permasalahan tersebut perlu penerapan metode baru untuk mendapatkan akurasi yang tinggi. Ada banyak penelitian yang menangani masalh pemeriksaan kualitas pada buah-buahan. Salah satu metode penelitian sebelumnya yaitu dengan memanfaatkan teknologi pengolahan citra digital. Citra digital adalah sebuah representasi numerik (biasanya biner) dari gambar dua dimensi. Sebuah gambar dapat didefinisikan sebagai fungsi dua dimensi $\mathrm{f}(\mathrm{x}, \mathrm{y})$, di mana $\mathrm{x}$ dan $\mathrm{y}$ adalah koordinat bidang datar, dan harga fungsi $\mathrm{f}$ dari setiap pasangan koordinat $(\mathrm{x}, \mathrm{y})$ disebut intensitas atau level keabuan (gray level) dari sebuah gambar. Ketika $\mathrm{x}, \mathrm{y}$, dan nilai intensitas $\mathrm{f}$ terbatas dengan nilai diskrit, maka gambar tersebut dapat dikatakan sebagai citra digital (Gonzalez et al, 2002). Tujuan dari pengolahan citra antara lain dapat memperbaiki kualitas gambar dilihat dari aspek radiometrik (peningkatan kontras, transformasi warna, restorasi citra) dan dari aspek geometrik (rotasi, translasi, skala, transformasi geometrik). Selain itu juga pengolahan citra dilakukan untuk proses penarikan informasi atau deskripsi objek atau pengenalan objek yang terkandung pada citra (Hermawati, 2013).

Metode pengolah citra digital juga diterapkan dalam metode klasifikasi deep learning. Deep learning adalah sebuah bidang keilmuan baru 
dalam bidang machine learning. Deep learning memiliki kemampuan yang sangat baik dalam visi computer. Salah satunya adalah pada kasus kalsifikasi objek pada citra. Dengan mengimplemantasikan salah satu metode machine learning yang dapat digunakan untuk klasifikasi citra objek yaitu Convolution Neural Network (CNN). Metode ini juga memiliki modifikasi berupa Deep Conolution Neural Network yang merupakan awal mula dari deep learning.(Krizhevsky,2012) Metode CNN ada dua tahap yaitu backpropagation dan feedforward. Sebelum klasifikasi di lakukan proses wraping dan cropping untuk memfokuskan objek.

Metode pendekatan deep learning mengklasifikasi data dalam dua sesi yaitu sesi training dan testing. Pada sesi training mempelajari ekstrasi fitur dari setiap data supaya bisa membedakan suaru label dengan label yang lain. Pada sesi testing data-data yang diuji dapat dianalisa dari hasil sesi training. Maka dari itu, pendekatan deep learning dibutuhkan untuk menganalisa foto dari permukaan buah mananggis dan mengklasifikasi buah manggis dengan kategori cacat atau baik dengan akurasi yang tinggi.

\section{Metode Penelitian}

Penelitian tentang klasifikasi buah dengan menggunakan pengolahan citra sudah banyak dilakukan. Penelitian-penelitian tersebut menggunakan berbagai macam metode salah satunya dalam penelitan Khoje, dkk., (2013) tentang "Automated Skin Defect Identification System for Fruit Grading Based on Discrete Curvelet Transform" bertujuan mengembangkan metodologi untuk menilai kualitas permukaan buah secara obyektif dengan menggunakan analisis tekstur berdasarkan transformasi curvelet dengan resolusi citra rendah dan tinggi. Pengukuran tekstur berdasarkan transformasi curvelet menggunakan 4 ekstrasi ciri diantaranya energy, entropy, rata-rata (mean) dan standar deviasi (std). Keempat ekstrasi ciri tersebut menjadi variabel yang digunakan untuk menganalisa kualitas permukaan buah. Metode yang digunakan untuk mengklasifikasikan kualitas permukaan buah yaitu klasifikasi Support Vector Machine (SVM) dan Probabilistic Neural Networks (PNN) dengan membagi dua kategori yaitu sehat dan cacat.
Hasil penelitian menunjukkan bahwa akurasi terbaik dari klasifikasi SVM diperoleh dengan akurasi nilai $96 \%$.

Ranjit dkk., (2016) dalam penelitiannya "Identification and Classification of Fruit Diseases" penelitian ini bertujuan untuk mengidentifikasi dan mengklasifikasi penyakit buah. Dalam penelitian ini citra buah tersegmentasi menggunakan algoritma K-means dan C-meansclustering. Kemudian evaluasi kinerja algoritma segmentasi dilakukan dengan menggunakan parameter seperti Measure of over segmentation (MOS), Measure of undersegmentation (MUS), Measure of overlapping (MOL), Dice similarity measure (DSM), Errorrate $(E R)$. Hasil klasifikasi dari penelitian ini memiliki akurasi yang relatif lebih tinggi dalam semua kasus bila tersegmentasi menggunakan K-means dibandingkan algoritma Cmeansclustering.

Algoritma pembelajaran yang diimplementasikan dalam penelitian ini yaitu menggunakan salah satu arsitektur deep learning yaitu Convolutional Neural Network $(C N N)$ yang digunakan untuk memecahkan masalah klasifikasi data karena memiliki tingkat akurasi yang tinggi. Penerapan metode CNN pernah dilakukan dalam penelitian Socher, dkk (2012). Di mana dalam penelitiannya "Convolutional-Recursive Deep Learning for 3D Object Classification" mengkombinasikan jaringan syaraf convolutional dan rekursif (CNN dan $\mathrm{RNN}$ ) sebagai fitur pembelajaran dan klasifikasi gambar RGB-D. Lapisan CNN mempelajari fitur invarian bawaan tingkat rendah yang kemudian sebagai input dari beberapa fixed-tree $R N N$ yang digabungkan menjadi fitur yang tinggi. Dari penelitian tersebut menghasilkan RNN dengan bobot yang acak sebagai fitur yang canggih sehingga diperoleh kinerja yang mutakhir pada dataset objek standar RGB-D menjadi lebih akurat dan cepat selama training dan testing dibandingkan arsitektur yang sebanding seperti CNN dengan dua lapisan.

Putra dkk (2016) dalam penelitiannya "Klasifikasi Citra Menggunakan Convolutional Neural Networks (CNN) pada Caltech 101" menerapkan salah satu metode deep learning yaitu dengan $\mathrm{CNN}$ untuk mengklasifikasi citra objek. Dalam metode penelitian yang digunakan dalam algoritma CNN terdapat 3 lapisan yang diimplementasikan, yaitu convolutional layer, subsampling layer, dan 
fully connected layer. Metode dalam penelitiannya terlebih dahulu dilakukan proses pengolahan pada data citra untuk memfokuskan objek yang akan diklasifikasi dengan metode wrapping dan cropping. Selanjutnya melakukan proses training dan testing dengan menggunakan algoritma CNN. Hasil uji coba dari klasifikasi citra objek dengan tingkat confusion yang berbeda pada basis data Caltech 101 menghasilkan nilai akurasi sebesar 20\% hingga $50 \%$.

Zufar (2016) dalam penelitiannya "Convolutional Neural Networks Untuk Pengenalan Wajah Secara Real-Time" menggunakan salah satu metode deep learning yaitu Convolutional Neural Networks (CNN). Dalam penelitiannya metode tersebut diimplementasikan dengan bantuan library OpenCV untuk mendeteksi multi wajah dan perangkat Web Cam M-Tech 5MP. Dalam penelitiannya uji coba yang dilakukan menggunakan kontruksi model CNN sampai kedalaman tujuh lapisan. Klasifikasi dilakukan dengan data input dari hasil ekstraksi Extended Local Binary Pattern dengan radius 1 dan neighbor 15. Dengan mengimplementasi metode ini, hasil penelitian menunjukkan kinerja pengenalan wajah meraih rata-rata tingkat akurasi lebih dari $89 \%$ dalam kurang lebih 2 frame per detik.vBeberapa peneliti lainnya seperti (Ngiam, 2011) telah melakukan analisa deep learning dengan multimodal. Dalam penelitiannya, deep learning menggunakan banyak parameter dan modal untuk mengolah data.

Dari hasil analisa berbagai penelitian yang sudah dilakukan terdahulu akan dilakukan riset tentang penerapan pengolahan citra untuk mendeteksi kecacatan permukaan buah manggis menggunakan metode Deep Learning. Metode ini digunakan untuk memecahkan masalah klasifikasi data karena penggunaannya yang memiliki proses komputasi yang relatif cepat, sehingga penelitian ini dapat menghasilkan deteksi cacat pada permukaan buah manggis berbasis pengolahan citra ini dapat membantu dalam peningkatan kualitas buah manggis.
Deep learning adalah cabang ilmu dari machine learning berbasis jaringan saraf tiruan (JST) atau bisa dikatakan perkembangan dari JST. Perbedaan dengan JST sendiri adalah banyaknya hidden layer pada deep learning yang di modelkan sedemikian rupa sehingga mampu memberikan output yang lebih akurat. Deep learning mengajari komputer melakukan sesuatu yang natural seperti manusia dan memiliki beberapa algoritma. Deep learning menemukan struktur yang rumit dalam kumpulan data yang besar dengan menggunakan algoritma backpropagation untuk menunjukkan bagaimana sebuah mesin harus mengubah parameter internalnya yang digunakan untuk menghitung representasi pada setiap lapisan dari representasi pada lapisan sebelumnya (LeCun, et. al, 2015).

Salah satu algoritma deep learning yang digunakan dalam penelitian ini adalah convolutional neural network dimana dapat memproses data 2 dimensi, misalnya gambar. Convolutional neural network ini diklaim sebagai algoritma terbaik dan paling banyak digunakan untuk mendeteksi objek dari data citra digital (Mathworks, 2017).

Langkah penelitian ini sesuai gambar 1 memiliki beberapa tahap. Setelah data-data dikalsifikasiakan secara manual, kemudian dilakukan perancangan program dimana program harus sesuai dengan kebutuhan. Setelah itu melakukan penyusunan program dimana algoritma di implementasi menggunakan toolbox dari software Matlab (Sianipar, 2013). Proses selanjutnya adalah melakukan proses forward propagation yang dilanjutkan dengan backpropagation. Selanjutnya melakukan pengujian program yang telah di buat terhadap citra. Apabila akurasi program masih kurang baik maka dilakukan perbaikan pada kode program hingga mendapatkan akurasi yang tinggi. Melihat dari hasil yang keluar dari progam dilakukan analisis lebih dalam sehingga dapat menghasilkan akuransi yang lebih baik. Setelah itu tahap analisa dan pembahasan hasil pengujian. 


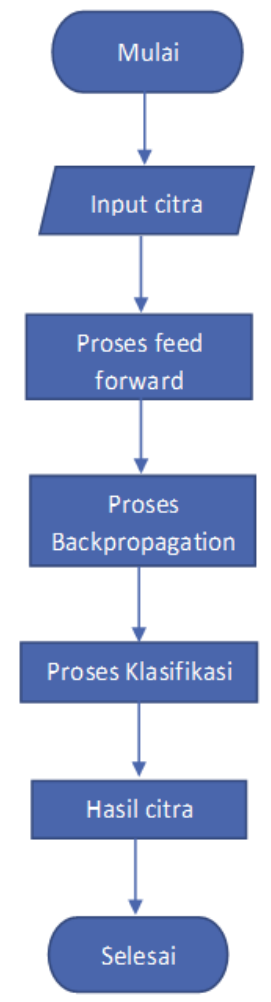

GAMBAR 1. Flowchart proses pengolahan data.

\section{HASIL DAN PEMBAHASAN}

Data manggis berupa gambar manggis dengan permukaan cacat dan gambar manggis dengan permukaan yang baik. Manggis dengan permukaan cacat memiliki nama gambar 'defect' dan permukaan manggis yang baik memiliki nama gambar 'fine'. Dilakukan training data dengan 120 data gambar yang terdiri dari 4 fold. Setiap fold memiliki 30 gambar dengan 24 gambar fine dan 6 defect dalam setiap fold.

Ukuran standar data citra pada penelitian ini adalah 214 x 214 piksel, sehingga seluruh data foto yang akan digunakan untuk penelitian ini melalui tahap proses cropping agar seluruh data citra ukurannya seragam. Setelah dilakukan proses cropping, disamakan ukuran sebesar 214 x 214 piksel. Proses ini dilakukan untuk mempermudah pengambilan data citra agar lebih akurat.

Setelah dilakukan proses cropping, proses selanjutnya adalah memilah data citra yang di anggap cacat dan tidak cacat dengan pengamatan secara langsung atau secara visual. Beberapa sampel hasil proses cropping dari citra yang akan menjadi bahan penelitian ditunjukan pada Gambar 2 dan Gambar 3

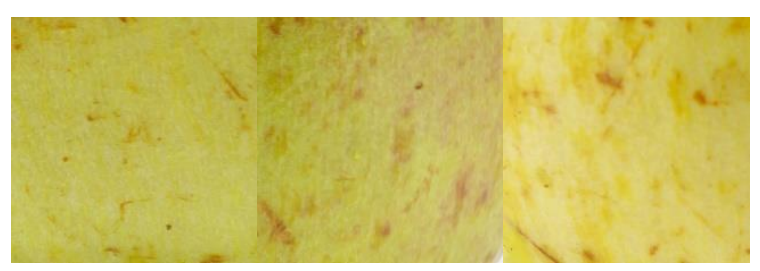

GAMBAR 2. Data citra tidak cacat

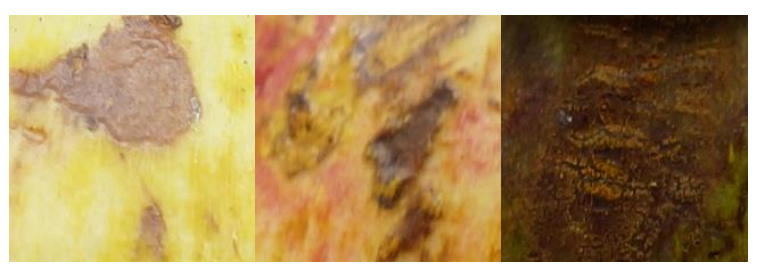

GAMBAR 3. Data citra cacat 
Data tersebut kemudian diolah dengan proses forward propogation dan back propogation. Penggunaan pooling layer pada CNN hanya bertujuan untuk mereduksi ukuran citra sehingga dapat dengan mudah digantikan dengan sebuah convolution layer dengan stride yang sama dengan pooling layer yang bersangkutan (Springenberg et al, 2014). Perubahan pooling dan stride pada penelitian ini disamakan guna memaksimalkan multiyaler yang ada. Dari data tersebut, kami melakukan beberapa percobaan untuk melihat perbedaan dalam tiap tiap running program.

Percobaan dilakukan dengan menambah epoch, layer ataupun data. Dalam mid proses ini data masih 120 data, kedepannya akan diolah 200 data tanpa fold. Epoch yang digunakan saat ini juga masih kecil. Dalam proses berikutnya akan merubah epoch yang besar. Selain Epoch juga ditambahkan layer ke dalam proses pengolahan data. Hasil data akurasi dalam mid proses dapat dilihat pada Tabel 1.

Setiap layer dan Epoch, dilakukan sepuluh kali percobaan. Dalam sepuluh kali melakukan perobaan dibuat rata rata akuransi yang ada.
Kemudian, meningkatkan layer yang ada di setiap epoch hingga layer tingkat 6 . Selain itu, epoch juga ditambah 5. Epoch adalah satu cycle untuk deep learning melakukan proses pengolahan citra. Dari tabel 1, layer tingkat 1 memiliki hasil terbaik di epoch 40 dimana nilai nya paling mendekati $100 \%$. Untuk hasil di layer 2, epoch 10 memiliki nilai maksimal, namun dari hasil tersebut juga dapat dilihat bahwa dari epoch 20 hingga epoch 40 memiliki hasil yang teratur dan cenderung stabil sehingga bisa dipastikan bahwa hasil tersebut memberikan hasil optimal terus menerus. Pada layer 3 dan seterusnya bahwa hasil tersebut memberikan hasil optimal di epcoh 10 dan di epoch 40. Dari hasil tersebut juga dibuat grafik yang dapat menunjukkan bahwa rata-rata akuransi menjadi semakin baik diantara epoch 10 hingga 30. Gambar 4 memperlihatkan bahwa hasil akuransi stabil dalam epoch 10 hingga 30 dengan layer 3 hingga 5. Namun untuk epcoh 40 penambahan layer menyebabkan penurunan akuransi data. Beberapa penyebab dimungkinkan terjadi karena penambahan ke layer 6 tidak banyak memberikan hasil yang maksimal untuk pengolahan data.

TABEL 1. Rata rata akuransi dari Epoch dan layer berbeda

\begin{tabular}{lrrrrr}
\hline Layer & \multicolumn{5}{c}{ Epoch } \\
\hline & 5 & 10 & 20 & 30 & 40 \\
1 & 0.9767 & 0.9967 & 0.9933 & 0.9959 & 0.9983 \\
2 & 0.9867 & 0.9975 & 0.9934 & 0.9934 & 0.9933 \\
3 & 0.9942 & 0.9950 & 0.9925 & 0.9967 & 0.9975 \\
4 & 0.9975 & 0.9925 & 0.9917 & 0.9934 & 0.9967 \\
5 & 0.9818 & 0.9925 & 0.9950 & 0.9933 & 0.9925 \\
6 & 0.9825 & 0.9933 & 0.9917 & 0.9908 & 0.9892 \\
\hline
\end{tabular}

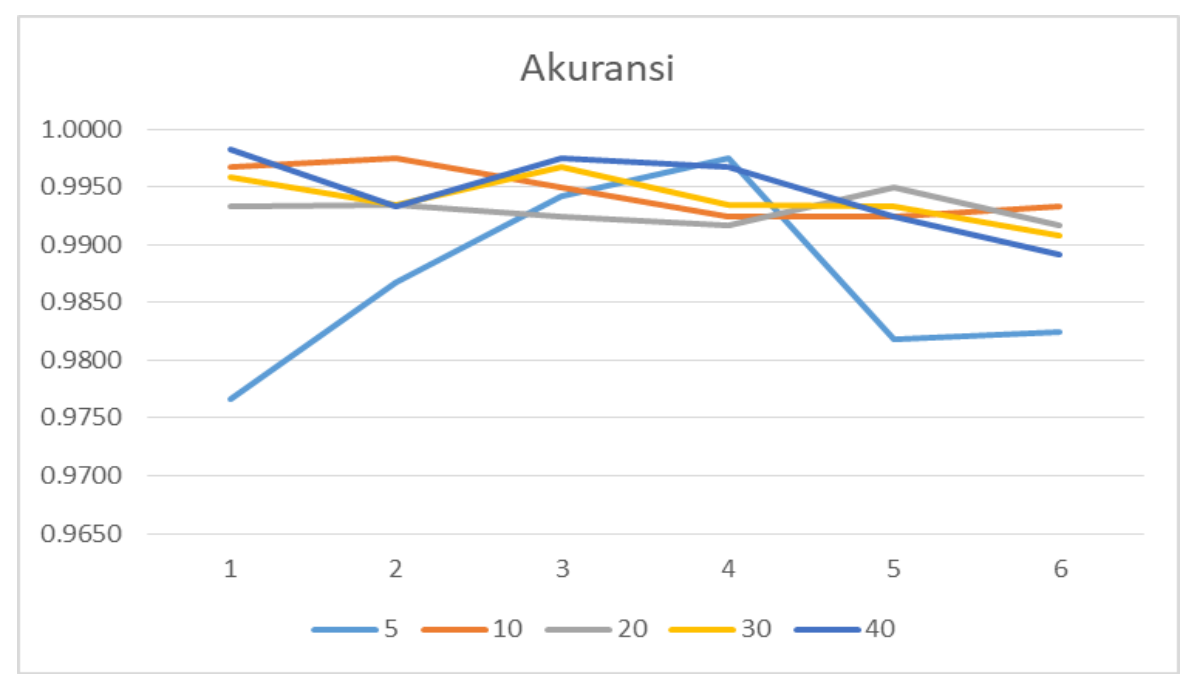

GAMBAR 4. Grafik hubungan antara layer, epoch dan akuransi dari hasil pengolahan citra digital 


\section{KESIMPULAN}

Dari penelitian ini dapat disimpulkan beberapa hal dalam penerapan metode deep learning dengan multilayer untuk mendeteksi kecacatan permukaan buah mangis, yaitu: . Sistem deteksi citra cacat permukaan buah manggis yang dikembangkan pada penelitian ini dapat mendeteksi cacat permukaan buah manggis dengan cukup baik setelah dilakukan pengujian sistem yang menghasilkan akurasi optimal dengan rata rata $98 \%$. Akuransi paling stabil dan paling baik untuk melakukan klasifikasi kecatatan adalah pengolahan data pada layer 3 hingga layer 5 dengan epoch 10 hingga 40 . Layer 4 dengan epoch 30 merupakah pemilihan layer yang paling stabil untuk pengolahan data digital buah manggis ini. Penambahan epoch terbukti memberikan hasil yang lebih optimal

Saran untuk penelitian selanjutnya yang berkaitan dengan penelitian ini, yaitu: Menguji dengan parameter lain pada klasifikasi CNN yang selanjutnya dikombinasikan dengan ekstraksi fitur yang paling sesuai untuk digunakan pada proses klasifikasi sehingga menghasilkan akurasi optimal. Penambahan Epoch untuk hasil lebih optimal. Memaksimalkan jumlah data hingga 1000 gambar data dengan kualitas foto high quality.

\section{UCAPAN TERIMA KASIH}

Penulis mengucapan terima kasih kepada pihakpihak yang telah membantu dalam penelitian yang dipublikasikan dalam jurnal ini terutama Universitas Muhammadiyah Yogyakarta.

\section{DAFTAR PUSTAKA}

Balai Besar Penelitian dan Pengembangan Pascapanen Pertanian. (2010). Laporan Kinerja 2010. Bogor: Badan Penelitian dan Pengembangan Pertanian.

Gonzalez, R. C., \& Woods, R. E. (2002). Digital Image Processing. New Jersey: Pearson Education.

Hermawati, F. A. (2013). Pengolahan Citra Digital: Konsep dan Teori. Yogyakarta: Andi.

Khoje, S. A., Bodhe, S. K., \& Adsul, A. (2013). Automated Skin Defect Identification System for Fruit Grading Based on
Discrete Curvelet Transform. International Journal of Engineering and Technology (IJET), 5(4), 32513256.

Krizhevsky, A., Sutskever, I., \& Hinton, G. E. (2012). Imagenet Classification With Deep Convolutional Neural Networks. In Advances in neural information processing systems (pp. 1097-1105).

LeCun, Y., Bengio, Y., \& Hinton, G. (2015). Deep Learning. Nature, 521 (7533), 436444.

Mathworks. (2017). Convolutional Neural Network. Diambil kembali dari Mathworks:

https://www.mathworks.com/discovery/c onvolutional-neural-network.html

Ngiam, J., Khosla, A., Kim, M., Nam, J., Lee, H., \& Ng, A. Y. (2011). Multimodal deep learning. In Proceedings of the 28 th international conference on machine learning (ICML-11) (pp. 689696)Putra, W. S. E. (2016). Klasifikasi Citra Menggunakan Convolutional Neural Network (CNN) pada Caltech 101. Jurnal Teknik ITS, 5(1).

Ranjit, K. N., Chethan, H. K., \& Naveena, C. (2016). Identification and Classification of Fruit Diseases. International Journal of Engineering Research and Application (IJERA), pp.11 - 14).

Sianipar, R. (2013). Pemograman MATLAB dalam Contoh dan Terapan. Bandung: Penerbit Informatika.

Sindonews. (2014). Tiga jenis buah-buahan ini jadi andalan ekspor Indonesia. Diambil kembali dari Sindonews:https://ekbis.sindonews.com/r ead/853574 /34/tiga-jenis-buah-buahanini-jadi-andalan-ekspor-indonesia1397374803

Springenberg, J. T., Dosovitskiy, A., Brox, T., \& Riedmiller, M. (2014). Striving for Simplicity: The All Convolutional Net. ICLR-2015.

Socher, R., Huval, B., Bath, B., Manning, C. D., \& Ng, A. Y. (2012). ConvolutionalRecursive Deep Learning for 3D Object Classification. In Advances in Neural Information Processing Systems (pp. 656-664). 
Zufar, M., \& Setiyono, B. (2016). Convolutional Neural Networks untuk Pengenalan Wajah Secara Real-Time. Jurnal Sains dan Seni ITS, 5(2).

PENULIS:

Laila Marifatul Azizah

Program Studi Teknologi Informasi, Fakultas Teknik, Universitas Muhammadiyah Yogyakarta, Bantul, D. I. Yogyakarta.

Email: laila.m.azizah@umy.ac.id

Sitti Fadillah Umayah

Program Studi Teknologi Informasi, Fakultas Teknik, Universitas Muhammadiyah Yogyakarta, Bantul, D. I. Yogyakarta.

Email: sitti.fadillah.2013@ft.umy.ac.id

\section{Febriyana Fajar}

Program Studi Teknologi Informasi, Fakultas Teknik, Universitas Muhammadiyah Yogyakarta, Bantul, D. I. Yogyakarta.

Email: febriyana.fajar.2014@ft.umy.ac.id 